\title{
L-glutamine:D-fructose-6-phosphate Aminotransferase as a Key Protein Linked to Multidrug Resistance in $E$. coli KD43162
}

\author{
Sung-Eun Lee (D) - Tae-Jeon Jung • Byeoung-Soo Park • Byung-Woo Kim • \\ Eun-Woo Lee · Hye Jin Kim · Jong Hwa Yum*
}

Received: 21 May 2015 / Accepted: 27 May 2015 / Published Online: 30 September 2015

(C) The Korean Society for Applied Biological Chemistry 2015

\begin{abstract}
A microarray study has been employed to understand changes of gene expression in E. coli KD43162 resistant to ampicillin, ampicillin-sulbactam, piperacillin, piperacillin-tazobactam, cefazolin, cefepime, aztreonam, imipenem, meropenem, gentamicin, tobramycin, ciprofloxacin, levofloxacin, moxifloxacin, fosfomycin, and trimethoprim-sulfamethoxazole except for amikacin using disk diffusion assay. Using Sodium dodecyl sulphate-polyacrylamide gel electrophoresis and MALDI-TOF MS analyses, $36 \mathrm{kDa}$ of outer membrane proteins (OMPs) was found to be deleted in the multidrug resistant E. coli KD 43162. Microarray analysis was used to determine up- and down-regulated genes in relation to multidrug resistant E. coli KD43162. Among the up-regulated
\end{abstract}

\section{S.-E. Lee}

School of Applied Biosciences, Kyungpook National University, Daegu 702-701, Republic of Korea

T.-J. Jung

Department of Laboratory Medicine, Kosin University Gospel Hospital College of Medicine, Busan 614-714, Republic of Korea

\section{B.-S. Park}

Research Station, Nanotoxtech Inc., Ansan 426-901, Republic of Korea

B.-W. Kim · E.-W. Lee

Department of Life Science and Biotechnology, Dongeui University, Busan 614-714, Republic of Korea

H. J. Kim

Department of Department of Dental Hygiene, Dongeui University, Busan 614-714, Republic of Korea

\section{J. H. Yum}

Department of Clinical Laboratory Science, Dongeui University, Busan 614-714, Republic of Korea

*Corresponding author (J. H. Yum: auxotype@deu.ac.kr)

This is an Open Access article distributed under the terms of the Creative Commons Attribution Non-Commercial License (http://creativecommons. org/licenses/by-nc/3.0/) which permits unrestricted non-commercial use, distribution, and reproduction in any medium, provided the original work is properly cited. genes, these genes were corresponded to express the proteins as penicillin-binding proteins (PBPs), tartronate semialdehyde reductase, ethanolamine utilization protein, shikimate kinase I, allantoinase, predicted SAM-dependent methyltransferase, Lglutamine:D-fructose-6-phosphate aminotransferase (GFAT), phosphoglucosamine mutase, predicted $N$-acetylmannosamine kinase, and predicted $N$-acetylmannosamine-6-P epimerase. Up-regulation of PBPs, one of primary target sites of antibiotics, might be responsible for the multidrug resistance in E. coli with increasing amount of target sites. Up-regulation of GFAT enzyme may be related to the up-regulation of PBPs because GFAT produces $N$-acetylglucosamine, a precursor of peptidoglycans. One of GFAT inhibitors, azaserine, showed a potent inhibition on the growth of $E$. coli KD43162. In conclusion, up-regulation of PBPs and GFATs with the loss of 36 kDa OMP refers the multidrug resistance in E. coli KD 43162.

Keywords E. coli $\cdot$ genomics $\cdot$ L-glutamine:D-fructose-6phosphate aminotransferase $\cdot$ multidrug resistance

\section{Introduction}

Resistance to antimicrobial agents in clinical microorganisms has referred to the use of antimicrobials being in nothing but the name in treating infections. In recent being infected by microorganisms in hospitals or related institutions are widely accepted and reported wherever in the world including Korea (Lee et al., 2010; Lim et al., 2012). Additionally, some possibilities of the presence of antibiotic-resistant microorganisms in the stock products and in the feces of the livestock are cautiously reported (McEwen and Fedorka-Cray, 2002).

The mode of action of antibacterial agents contains inhibitory effect on cell wall synthesis, interference with protein synthesis, changes on nucleic acid synthesis, inhibitory effect on metabolic pathways, and finally disruption of membrane structure (Tenover, 
2006). Therefore, resistance mechanisms to antimicrobial agents in clinical microbes are related to overcome the mode of action of antimicrobial agents and divided into four primary groups in the basis of their biochemical changes (Tenover, 2006). Firstly, microbes acquire resistant genes encoding $\beta$-lactamases to metabolize antibacterial agent before it shows biological activity (Park et al., 2013). Secondly, bacteria acquire efflux systems which can extrude the antimicrobial agents from the cell before they are reached to the target sites (Richmond et al., 2013). Finally, bacteria acquire genes that produce altered cell walls (Yuan et al., 2013) and down-regulate porin genes to make antimicrobials with limited accession to target sites (Lavigne et al., 2013).

Recently, many scientists have contributed to develop new antimicrobials with novel target sites to suppress microbes (Kurosu et al., 2013; Sommer et al., 2013; Tegos and Hamblin, 2013). In addition to development of new antimicrobials, it is also interested in understanding changes in whole gene or protein expression in antimicrobials-resistant clinical microbes because modification of protein expression related to antimicrobial resistance can induce to change gene or protein expression (Chopra et al., 2013; Cierniak et al., 2013; Farrugia et al., 2013). This change can be a clue for finding new target site to control multidrug resistant microbes.

Herein, a genomic study has been employed to understand changes of gene expression in E. coli KD43162 resistant to antimicrobials. Using MALDI-TOF MS analysis, outer membrane proteins (OMPs) have been determined in the microbe. Microarray analysis was used to determine up- and down-regulated genes in relation to multidrug resistant $E$. coli KD43162. Finally, a novel inhibitor (azaserine) on L-glutamine:D-fructose-6-phosphate aminotransferase activity (GFAT) was determined to its potent inhibitory activity on E. coli 43162 growth.

\section{Materials and Methods}

Microbes used in this study. E. coli ATCC 25922 and E. coli ATCC 35218 were acquired from ATCC. E. coli KD43162 was found from a Korean patient. This strain was undertaken a susceptibility test and detection of beta-lactamase. The susceptibility test of selected antimicrobial agents were determined by disk diffusion method and Etest (AB bioMérieux, Sweden) (Thaller et al., 2011) using Mueller-Hinton agar (Oxoid, United Kingdom) according to the Clinical and Laboratory Standards Institute (CLSI) guidelines (CLSI, 2010). E. coli ATCC 25922 and E. coli ATCC 35218 were used as quality control. The imipenem-disk modified Hodge test and imipenem-EDTA+sodium mercaptoacetic acid double-disk synergy test was performed as described previously (Lee et al., 2003; Lee et al., 2010; Lee et al., 2001) by using known metallo- $\beta$-lactamase (MBL)-producing isolates. The polymerase chain reaction conditions for detection of carbapenemases genes were used to amplify several beta-lactamases ( $b l a_{\mathrm{VIM}}$, bla $a_{\mathrm{IMP}}$, $b l a_{\mathrm{SIM}}$, and $b l a_{\mathrm{AIM}}$ ) (Lee et al., 2005; Patzer et al., 2009). To detect or sequence $b l a_{\mathrm{NDM}}$ alleles, the following primers were used: NDM-1-F, 5'-TCG CAC CGA ATG TCT GGC AGC A-3'; NDM-1-R, 5'-AAA GCG ATG TCG GTG CCG TCG A-3'. Primers OmpF-F (5'-GCAGTGGCAGGTGTCATAAA-3')/OmpFR (5'-TCGGCATTTAACAAAGAGGTG-3') and OmpC-F (5'GCAGGCCCTTTGTTCGATA-3')/OmpC-R (5'-GCCGACTGAT TAATGAGGGTTA-3') were used to amplify the $o m p F$ (1158 bp) and the $\operatorname{ompC}$ (1236 bp) genes, respectively, in the E. coli KD43162 and E. coli ATCC 25922 by the method previously reported (Oteo et al., 2008). With the respect of multidrug resistance in the $E$. coli KD43162, the strain was resistant to ampicillin, ampicillinsulbactam, piperacillin, piperacillin-tazobactam, cefazolin, cefepime, aztreonam, imipenem, meropenem, gentamicin, tobramycin, ciprofloxacin, levofloxacin, moxifloxacin, fosfomycin, and trimethoprim-sulfamethoxazole except for amikacin using disk diffusion assay. Minimum inhibitory concentrations of imipenem and meropenem for the E. coli KD43162 were both $16 \mu \mathrm{g} / \mathrm{mL}$, respectively.

Sample preparation. Total RNA was extracted from the $E$. coli cell using the TRI REAGENT (MRC, OH) according to the manufacturer's instructions. Following homogenization, $1 \mathrm{~mL}$ of solution was transferred to a $1.5 \mathrm{~mL}$ Eppendorf tube and centrifuged at $12,000 \mathrm{~g}$ for 10 minutes at $4^{\circ} \mathrm{C}$ to remove insoluble material. The supernatant containing RNA was collected, mixed with $0.2 \mathrm{~mL}$ of chloroform, and centrifuged at $12,000 \mathrm{~g}$ for $15 \mathrm{~min}$ at $4^{\circ} \mathrm{C}$. After RNA in the aqueous phase was transferred into a new tube, the RNA was precipitated by mixing $0.5 \mathrm{~mL}$ of isopropyl alcohol and recovered by centrifuging the tube at $12,000 \mathrm{~g}$ for 10 $\min$ at $4^{\circ} \mathrm{C}$. The RNA pellet was washed briefly in $1 \mathrm{~mL}$ of $75 \%$ ethanol and centrifuged at 7,500 g for 5 minutes at $4^{\circ} \mathrm{C}$. Finally, the total RNA pellet was dissolved in Nuclease-water, and its quality and quantity was assessed by Agilent bioanalyzer 2100 analysis (Agilent technologies, USA).

Microarray analysis. Each total RNA sample using lug made sense RNA after cDNA synthesis by reverse transcription to proceed after the in vitro transcription process. Then amplified using sense RNA in the process of cDNA synthesis by reverse transcription proceeds given to put the labeled-dCTP fluorescent incorporation labeled cDNA made. The Cy3-labeled cDNAs were resuspended in $50 \mathrm{~mL}$ of hybridization solution (Agilent technologies). After labeled cDNAs were placed on Agilent E. coli $8 \times 15 \mathrm{~K}$ array

Table 1 Identification of outer-membrane proteins by MALDI-TOF MS. Numbering in the table for proteins is equal to the numbering in Fig. 1

\begin{tabular}{clllll}
\hline No. & \multicolumn{1}{c}{ Protein name } & Accession no. & Score $(p=0.05)$ & Species match & Gene ontology \\
\hline 1 & Outer membrane C & AAN81212 & $100(74)$ & E. coli CFT073 & Ion transport \\
2 & Outer membrane protein II & Q6WAH4_ECOLI & $60(58)$ & E. coli & Ion transport \\
3 & DNA protection during starvation protein & DPS_ECO57 & $64(58)$ & E. coli O157:H7 & Cellular iron ion homeostasis \\
\hline
\end{tabular}


(Agilent technologies) and covered by a Gasket 8-plex slide (Agilent technologies). The slides were hybridized for $17 \mathrm{~h}$ at $65^{\circ} \mathrm{C}$ oven. The hybridized slides were washed in $2 \times \mathrm{SSC}, 0.1 \%$ SDS for $2 \mathrm{~min}, 1 \times \mathrm{SSC}$ for $3 \mathrm{~min}$, and then $0.2 \times \mathrm{SSC}$ for $2 \mathrm{~min}$ at room temperature. The slides were centrifuged at $3,000 \mathrm{rpm}$ for $20 \mathrm{~s}$ to dry.

Data analysis. The arrays were analyzed using an Agilent scanner with associated software. Gene expression levels were calculated with Feature Extraction v10.7.3.1 (Agilent technologies). Relative signal intensities for each gene were generated using the Robust Multi-Array Average algorithm. The data were processed based on quantile normalization method using the GeneSpring GX 11.5.1 (Agilent technologies). This normalization method aims to make the distribution of intensities for each array in a set of arrays the same. The normalized, and log transformed intensity values were then analyzed using GeneSpring GX 11.5.1 (Agilent technologies). Fold change filters included the requirement that the genes be present in at least $200 \%$ of controls for up-regulated genes and lower than $50 \%$ of controls for down-regulated genes. Sodium dodecyl sulphate-polyacrylamide gel electrophoresis (SDS-PAGE) for OMP. SDS-PAGE was performed to determine alterations in outer membrane proteins, as described previously (Lee et al., 2007) but with some modification. Briefly, cells were disrupted by sonication and the supernatant was treated with $30 \%$ Sarkosyl (Sigma Chemical Co., USA) to solubilize the inner and outer membranes. Outer membranes were then sedimented by centrifugation at $45,000 \mathrm{~g}$ for $1 \mathrm{~h}$ at $4^{\circ} \mathrm{C}$ and outer membrane proteins were separated by SDS-PAGE on a Mini- PROTEAN 3 Cell apparatus (Bio-Rad, USA). The gels were stained with Coomassie Brilliant Blue and then de-stained.

Mass spectrometry. Digestion of selected gel portions was performed according to a previously reported method (Park et al., 2008). Protein spots were cut from the gels, and then the excised gels were washed 3 times for 20 min with $200 \mu \mathrm{L}$ of $60 \% \mathrm{v} / \mathrm{v} 50$ $\mathrm{mM}$ ammonium bicarbonate $(\mathrm{pH} 7.8)$ in $40 \% \mathrm{v} / \mathrm{v}$ acetonitrile at $37^{\circ} \mathrm{C}$. The stained gels were dehydrated in a SpeedVac for $20 \mathrm{~min}$. The remaining processes were exactly same from the method previously reported (Park et al., 2008).

Growth inhibition by addition of two GFAT inhibitors on multidrug resistant $\boldsymbol{E}$. coli KD43162. Cell growth of $E$. coli KD43162 in the absence of cefoxitin and in the presence of cefoxitin was undertaken. Two GFAT inhibitors, azaserin (Aza) and 6-diazo-5-oxo-L-norleucine (Don), were added to the growth medium to validate their inhibitory effects on the GFAT activity, referring to inhibition on cell growth. Two inhibitors were added to the growth medium at the concentrations of 100 and $250 \mathrm{ppm}$. Control indicates no addition of GFAT inhibitors.

Statistical analysis. Statistical analysis was performed using the SPSS for Windows statistical package, version 10.0 (SPSS Inc., USA). Data are expressed as mean \pm SD. The effects of drug treatments were evaluated statistically using the one-way analysis of variance (one-way ANOVA) followed by the Dunnett's posthoc test to rectify for multiple comparison treatments. Statistical significance was set at $p<0.05$.

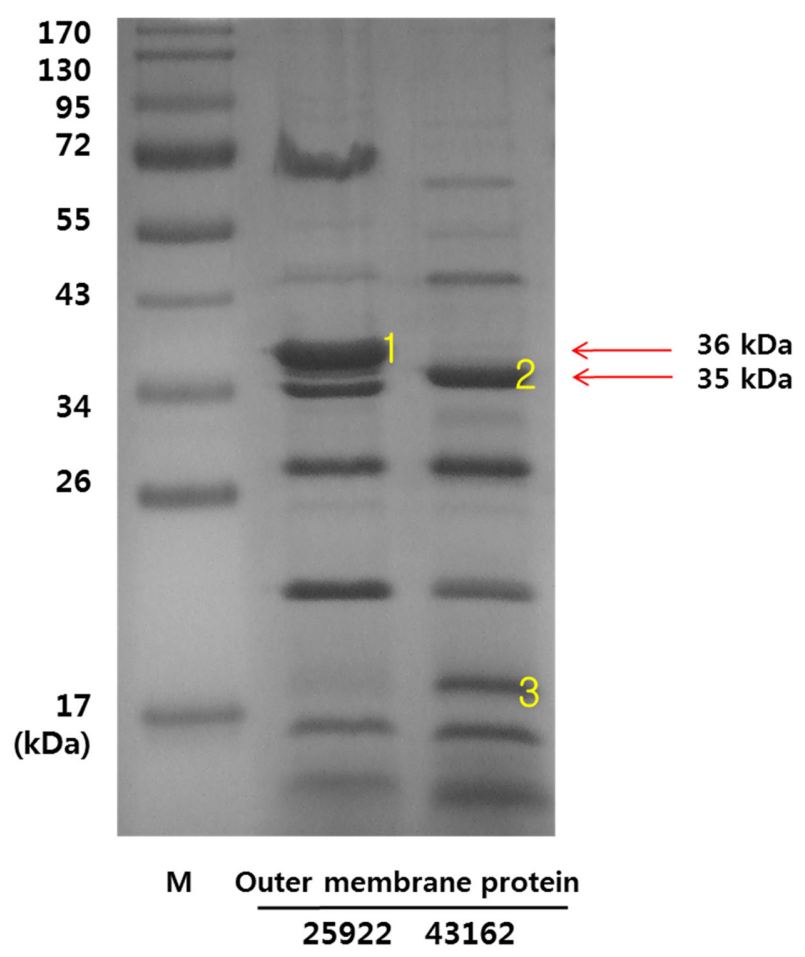

Fig. 1 Number of differentially expressed genes in E. coli 43162 after cefoxitin exposure. Number of significant up-and down-regulated genes (three samples $t$-tests, $p<0.05$ ) in $E$. coli KD 43162 after exposure to cefoxitin in three different concentrations of cefoxitin. Values refer to the comparison with the respective control.

\section{Results and Discussion}

SDS-PAGE of outer membrane proteins and MALDI-TOF MS analysis. The results of an imipenem-disk modified Hodge test and a double-disk synergy test using disks of imipenem and EDTA + sodium mercaptoacetic acid were negative, indicating production of a MBL, but bla $_{\mathrm{IMP}-1^{-}}, b l a_{\mathrm{VIM}-2^{-}}, b l a_{\mathrm{SIM}-1^{-}}, b l a_{\mathrm{AIM}-1^{-}}$or $b l a_{\mathrm{NDM}-1}-$ like, was not detectable by polymerase chain reaction. Lee et al. (2007) reported that CMY-2 or DHA-1 production combined with porin loss reduced carbapenem susceptibility in the $K$. pneumonia isolates. The OmpC gene was not detected by polymerase chain reaction from E. coli KD43162 but, OmpF gene was detectable. The loss of 36 and $35 \mathrm{kDa}$ OMP were coffered to carbapenem resistant in isolates. Two major porins, OmpF, and OmpC, have been reported the loss or diminished expression of these two porins have been related to resistance to imipenem, meropenem, and cefoxitin in E. coli (Clarke et al., 2003; Latigue et al., 2007; Liu et al., 2008). The loss of a $36 \mathrm{kDa}$ OMP conferred a high level of resistance to carbapenems upon the $E$. coli isolates (Liu et al., 2008). The OmpC was observed only in E. coli ATCC 25922, while an OmpF protein was observed in E. coli KD43162, as observed in Table 1 and Fig. 1, and in agreement with the our genetic study. OMP proteins were analyzed by MALDI-TOF MS as shown in Table 1.

Microarray analysis and validation. A gene list complied on the 


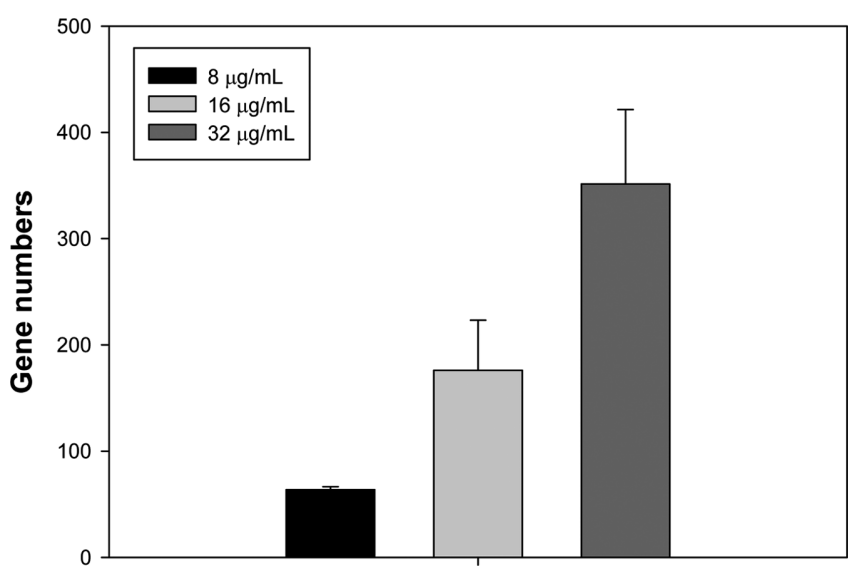

Fig. 2 Heat map and clustering analysis of cefoxitin samples. Heat map and hierarchical clustering of samples based on the differentially expressed genes (three samples $t$-test, $p<0.05$ ) in $E$. coli KD 43162 when comparing: A, control; B, $8 \mu \mathrm{g} / \mathrm{mL} ; \mathrm{C}, 16 \mu \mathrm{g} / \mathrm{mL} ; \mathrm{D}, 32 \mu \mathrm{g} / \mathrm{mL}$ of cefoxitin.

basis of statistical analysis $(p<0.05)$. Using the criteria, 1198 genes were identified including non-changed genes. Number of significant up-and down-regulated genes in E. coli KD43162 after exposure to cefoxitin in three different concentrations was determined and increased with increasing concentration of cefoxitin treatment (Fig. 2). Based on the differentially expressed genes, a heat map and hierarchical clustering of samples was established in $E$. coli KD43162 with different concentrations of cefoxitin addition in the E. coli growth medium (Fig. 3).

Among them, genes at least 2-fold up-regulated in the resistant E. coli KD43162 were listed in Table 2. These genes were corresponded to express the proteins as penicillin-binding protein, tartronate semialdehyde reductase, ethanolamine utilization protein, shikimate kinase I, allantoinase, predicted SAM-dependent methyltransferase, L-glutamine:D-fructose-6-phosphate aminotransferase, phosphoglucosamine mutase, predicted $\mathrm{N}$-acetylmannosamine kinase, and predicted $N$-acetylmannosamine-6-P epimerase. Peptidoglycans surround most bacteria, referring bacterial shape and protecting them against high osmotic pressure (Vollmer et al., 2008). They are net-like macromolecules and assembled by the membrane-bound peptidoglycans glycosyltransferases and transpeptidases. The penicillin-type antimicrobials

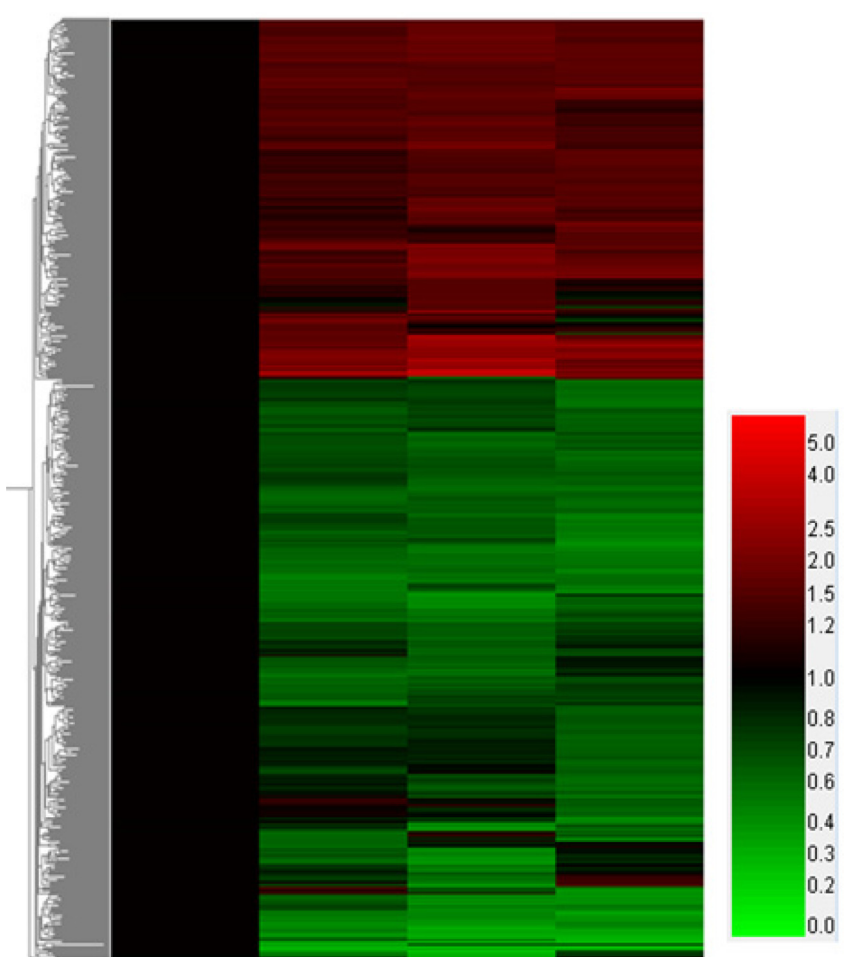

Fig. 3 Sodium dodecyl sulphate-polyacrylamide gel electrophoresis profiles of outer membrane protein. Lane M, marker; lane 25922, control E. coli ATCC 25922; lane 43162, E. coli KD 43162.

combine to the transpeptidases and inhibit the peptidoglycan formation (Derouaux et al., 2011). Bacterial peptidoglycan transpeptidases are known as penicillin-binding proteins (PBPs) and they are found to be up-regulated in the multidrug-resistant $E$. coli KD43162 in this study. It is an interesting result because the target site of antibiotics was up-regulated and this up-regulation might refer the bacteria to survive under the recommended treating doses of antibiotics. However, it is different result from the well-known resistance mechanism in relation to PBPs as the modification of the PBPs in the cell wall with low affinity for $\beta$-lactams (Zapun et al., 2008). This resistance mechanism is well-organized in the Gram-positive cocci, such as penicillin-resistant Streptococcus pneumonia or the much-feared methicillin-resistant Staphylococcus

Table 2 List of representative genes up-regulated in E. coli KD 43162 after treatment of cefoxitin

\begin{tabular}{cclll}
\hline No. & Gene Symbol & \multicolumn{1}{c}{ Gene name } & Fold to control & Gene ontology \\
\hline 1 & pbpC & penicillin-binding protein 1C & $7.22( \pm 0.86)$ & Peptidoglycan biosynthetic process \\
2 & garR & tartronate semialdehyde reductase & $5.66( \pm 1.31)$ & Glyoxylate metabolic process \\
3 & eutH & ethanolamine utilization protein & $3.56( \pm 0.55)$ & Ethanolamine catabolic process \\
4 & aroK & shikimate kinase I & $2.16( \pm 0.23)$ & Aromatic amino acid family biosynthetic process \\
5 & Z0666 & allantoinase & $4.89( \pm 1.11)$ & Purine metabolism \\
6 & yhiQ & predicted SAM-dependent methyltransferase & $4.57( \pm 1.61)$ & Methyltransferase \\
7 & glmS & L-glutamine:D-fructose-6-phosphate aminotransferase & $6.17( \pm 3.38)$ & UDP-N-acetylglucosamine biosynthetic process \\
8 & glmM & phosphoglucosamine mutase & $2.12( \pm 0.03)$ & UDP-N-acetylglucosamine biosynthetic process \\
9 & nanK & predicted $N$-acetylmannosamine kinase & $2.55( \pm 0.54)$ & Kinase activity \\
10 & nanE & predicted $N$-acetylmannosamine-6-P epimerase & $3.31( \pm 1.34)$ & Predicted \\
\hline
\end{tabular}


(A)<smiles>CN=[N+]=CC(=O)OC[C@H](N)C(=O)O</smiles>

(B)<smiles>CN=[N+]=CC(=O)CC[C@H](N)C(=O)O</smiles>

Fig. 4 Structures of (A) azaserine and (B) 6-diazo-5-oxo-L-norleucine (DON)

aureus (Zapun et al., 2008). Recently, this resistance mechanism is also reported in the Gram-negative rods (GNRs) as Psedomonas aeruginosa, which it has not been thought to be important in GNRs (Moya et al., 2009). On the other hand, a recent study strongly showed a relationship between down-regulation of PBPs and alteration in PBPS for $\beta$-lactam resistance in Acinetobacter baumannii (Vashist et al., 2011). Therefore, our result differs from those two resistant mechanisms and it is first to report the upregulation of PBPs in relation to antibiotic resistant mechanisms in E. coli $\mathrm{KD} 43162$.

Up-regulation of PBPs may lead over-production of precursors of peptidoglycans in the microbes. The precursors of peptidoglycans in microbes are $\mathrm{N}$-acetylglucosamine (Glc-Nac) and $\mathrm{N}$-acetylmuramic acid (MurNAc)-peptide attached to the membrane-bound lipid synthesized inside the bacterial cell (Barreteau et al., 2008). In this study, the enzymes such as GFAT and phosphoglucosamine mutase were found to be up-regulated and they might be involved in the presumable over-production of Glc-Nac in the multidrug resistant E.coli KD43162. As PBPs play an important role in antibiotics target sites, inhibition of Glc-Nac production is a potential target site for novel anti-infective agents (Ramos-Aires et al., 2004). As up-regulation of $g l m S$ responsible for the expression of L-glutamine:D-fructose-6-phosphate aminotransferase was established in this study, an inhibitor on the enzyme activity might inhibit to form Glc-Nac, leading to kill the multidrug resistant $E$. coli KD43162 cells via inhibition of production of PBPs.

Two potent, specific inhibitors on GFAT activity, azaserine (Aza) and 6-diazo-5-oxo-L-norleucine (Don) (Fig. 4), were employed to confirm our suggestions on the control of the multidrug resistant E. coli KD 43162 by suppressing of PBPs through less production of Glc-Nac. Interestingly, Aza with the concentrations of 100 and 250 ppm completely suppressed the E. coli KD43162 growth, while Don did not show potent inhibitory effects on the microbial growth at the two concentrations with or without cefoxitin (Fig. 5). It might be resulted from the different affinity to the GFAT active site of E. coli KD43162, even if they are potent GFAT
(A)

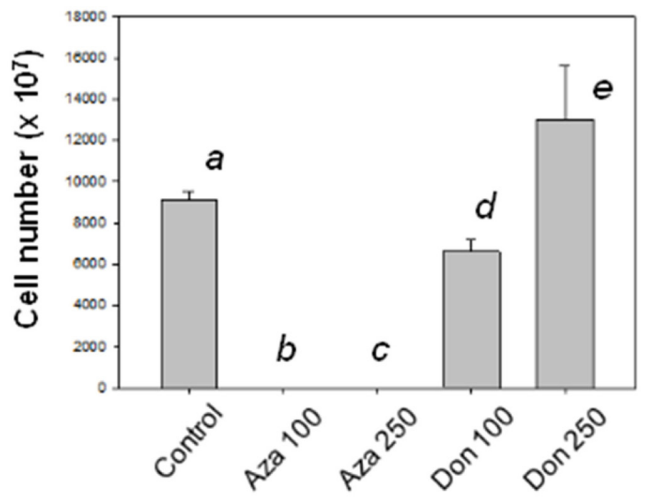

(B)

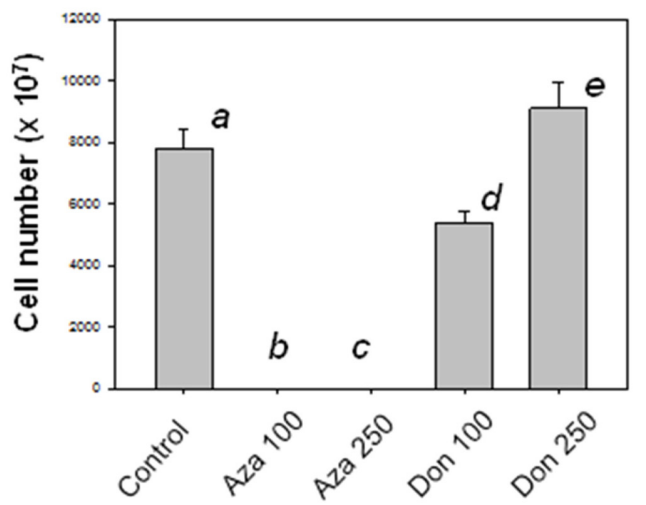

Fig. 5 Cell growth of E. coli KD43162 in the absence of cefoxitin (A) and in the presence of cefoxitin (B). Two inhibitors of L-glutamine:Dfructose-6-phosphate aminotransferase inhibitors, azaserine (Aza) and 6diazo-5-oxo-L-norleucine (Don), were added to the growth medium at the concentrations of 100 or $250 \mathrm{ppm}$. Control indicates no addition of Lglutamine:D-fructose-6-phosphate aminotransferase inhibitors. Data followed by the same letter are not significantly different $(p<0.05)$.

inhibitors in other organisms (Dehennaut et al., 2007). Further studies will focus on the assessment of relationship between two inhibitors and the E. coli GFAT active sites and develop possible synthetic scheme to produce antibiotics to control multidrug resistant microbes via selective inhibition on microbial GFAT activity.

Other up-regulated genes are responsible for the expression of proteins involved in glyoxylate metabolic process, ethanolamine catabolic process, aromatic amino acid biosynthetic process, purine metabolism, and methyltransferase. They are possible target sites for antibiotics to suppress multidrug resistant E. coli KD43162. Therefore, up-regulation of PBPs and GFATs, and loss of $36 \mathrm{kDa}$ OMP may confer the multidrug resistance in E. coli KD43162.

Acknowledgments This work was supported by Blue-Bio Industry Regional Innovation Center (RIC08-06-07) at Dongeui University as a RIC program under Ministry of Trade, Industry\&Energy and Busan city.

\section{References}

Barreteau H, Kovac A, Boniface A, Sova M, Gobec S, and Blanot D (2008) 
Cytoplasmic steps of peptidoglycan biosynthesis. FEMS Microbiol Rev 32, 161-207.

Chopra S, Ramkissoon K, and Anderson DC (2013) A systematic quantitative proteomic examination of multidrug resistance in Acinetobacter baumannii. J Proteomics 84, 17-39.

Cierniak P, Jubner M, Muller S, and Bender K (2013) Insights into mechanisms and proteomic characterization of Pseudomonas aeruginosa adaptation to a novel antimicrobial substance. PLoS One 8, e66862.

Clarke B, Hiltz M, Musgrave H, and Forward KR (2003) Cephamycin resistance in clinical isolates and laboratory-derived strains of Escherichia coli, Nova Scotia, Canada. Emerg Infect Dis 9, 1254-9.

CLSI (2010) Performance standards for antimicrobial susceptibility testing:Twenty-first informational supplement. Clinical and Laboratory Standards Institute, USA.

Dehennaut V, Lefebvre T, Sellier C, Leroy Y, Gross B, Walker S et al. (2007) $O$-liked $N$-acetylglucosaminetransferase inhibition prevents $\mathrm{G}_{2} / \mathrm{M}$ transition in Xenopus laevis oocytes. J Biol Chem 282, 12527-36.

Derouaux A, Turk S, Olrichs NK, Gobec S, Breukink E, Amoroso A et al. (2011) Small molecule inhibitors of peptidoglycan synthesis targeting the lipid II precursor. Biochem Pharmacol 81, 1098-105.

Farrugia DN, Elbourne LD, Hassan KA, Eijkelkamp BA, Tetu SG, Brown $\mathrm{MH}$ et al. (2013) The complete genome and phenome of a communityacquired Acinetobacter baumannii. PLoS One 8, e58628.

Kurosu M, Siricilla S, and Mitachi K (2013) Advances in MRSA drug discovery: where are we and where do we need to be? Expert Opin Drug Discov 8, 1095-116.

Latigue MF, Poirel L, Poyart C, Reglier-Poupet H, and Nordmann P (2007) Ertapenem resistance of Escherichia coli. Emerg Infect Dis 13, 315-7.

Lavigne JP, Sotto A, Nicolas-Chanoine MH, Bouziges N, Pagès JM, and Davin-Regli A (2013) An adaptive response of Enterobacter aerogenes to imipenem: regulation of porin balance in clinical isolates. Int $J$ Antimicrob Agents 41, 130-6.

Lee K, Chong Y, Shin HB, Kim YA, Yong D, and Yum JH (2001) Modified Hodge test and EDTA-disk synergy tests to screen metallo-betalactamase-producing strains of Pseudomonas and Acinetobacter species. Clin Microbiol Infect 7, 88-91.

Lee K, Kim CK, Yong D, Jeong SH, Yum JH, Seo YH et al. (2010) Improved performance of the modified Hodge test with MacConkey agar for screening carbapenemase-producing Gram-negative bacilli. J Microbiol Methods 83, 149-52.

Lee K, Lim YS, Yong D, Yum JH, and Chong Y (2003) Evaluation of the Hodge Test and the Imipenem-EDTA Double-Disk Synergy Test for Differentiating Metallo-beta-Lactamase-Producing Isolates of Pseudomonas spp. and Acinetobacter spp. J Clin Microbiol 41, 4623-9.

Lee K, Yong D, Choi YS, Yum JH, Kim JM, Woodford N et al. (2007) Reduced imipenem susceptibility in Klebsiella pneumonia clinical isolates with plasmid-mediated CMY-2 and DHA-1 $\beta$-lactamases comediated by porin loss. Int J Antimicrob Agents 29, 201-6.

Lee K, Yum JH, Yong D, Lee HM, Kim HD, Docquier JD et al. (2005) Novel acquired metallo- $\beta$-lactamase gene, $b l a_{\mathrm{SIM}-1}$, in a class 1 integron from Acinetobacter baumannii clinical isolates from Korea. Antimicrob Agents Chemother 49, 4485-91.

Lim SK, Park IW, Lee WG, Kim HK, and Choi YH (2012) Change of antimicrobial susceptibility among Escherichia coli strains isolated from female patients with community-onset acute pyelonephritis. Yonsei Med $J$ 53, 164-71.

Liu YF, Yan JJ, Ko WC, Tsai SH, and Wu JJ (2008) Characterization of carbapenem-non-susceptible Escherichia coli isolates from a university hospital in Taiwan. J Antimicrob Chemother 61, 1020-3.

McEwen SA and Fedorka-Cray PJ (2002) Antimicrobial use and resistance in animals. Clin Infect Dis 34(S3), S93-S106.

Moya B, Dotsch A, Juan C, Blazquez J, Zamorano L, Hausslr S et al. (2009) $\beta$-lactam resistance response triggered by inactivation of nonessential penicillin-binding protein. PLoS Pathogen 5, e1000353.

Oteo J, Delgado-Iribarren A, Vega D, Bautista V, Rodriguez MC, Velasco M et al. (2008) Emergence of imipenem resistance in clinical Escherichia coli during therapy. Int J Antimicrob Agents 32, 534-7.

Park BS, Lee BH, Kim TW, Ren Y, and Lee SE (2008) Proteomic evaluation of adults of Rhyzopertha dominica resistant to phosphine. Envrion Toxicol Pharmacol 25, 121-6.

Park MJ, Kim TK, Song W, Kim JS, Kim HS, and Lee J (2013) An increase in the clinical isolation of acquired AmpC $\beta$-lactamase-producing Klebsiella pneumonia in Korea from 2007 to 2010. Ann Lab Med 33, 353-5.

Patzer JA, Walsh TR, Weeks J, Dzierzanowska D, and Toleman MA (2009) Emergence and persistence of integron structures harbouring VIM genes in the Children's Memorial Health Institute, Warsaw, Poland, 19982006. J Antimicrob Chemother 63, 269-73.

Ramos-Aires J, Plésiat P, Kocjancic-Curty L, and Köhler T (2004) Selection of an antibiotic-hypersusceptible mutant of Pseudomonas aeruginosa: identification of the GlmR transcriptional regulator. Antimicrob Agents Chemther 48, 843-51.

Richmond GE, Chua KL, and Piddock LJ (2013) Efflux in Acinetobacter baumannii can be determined by measuring accumulation of $\mathrm{H} 33342$ (bis-benzamide). J Antimicrob Chemother 68, 1594-600.

Sommer R, Joachim I, Wagner S, and Titz A (2013) New approaches to control infections: anti-biofilm strategies against gram-negative bacteria. Chimia 67, 286-90.

Tegos GP and Hamblin MR (2013) Disruptive innovations: new antiinfectives in the age of resistance. Curr Opin Pharmacol 13, 673-7.

Tenover FC (2006) Mechanisms of antimicrobial resistance in bacteria. Am J Med 119, S3-S10.

Thaller MC, Borgianni L, Di Lallo G, Chong Y, Lee K, Dajcs J et al. (2011) Metallo- $\beta$-lactamase production by Pseudomonas otitidis: a speciesrelated trait. Antimicrob Agents Chemother 55, 118-23.

Vashist J, Tiwari V, Das R, Kapil A, and Rajeswari MR (2011) Analysis of penicillinbinding proteins (PBPs) in carbapenem resistant Acinetobacter baumannii. Indian J Med Res 133, 332-8.

Vollmer W, Blanot D, and De Pedro MA (2008) Peptidoglycan structure and architecture. FEMS Microbiol Rev 32, 149-67.

Yuan W, Hu Q, Cheng H, Shang W, Liu N, Hua Z et al. (2013) Cell wall thickening is associated with adaptive resistance to amikacin in methicillin-resistant Staphylococcus aureus clinical isolates. J Antimicrob Chemother 68, 1089-96.

Zapun A, Contreras-Martel C, and Vernet T (2008) Penicillin-binding proteins and $\beta$-lactam resistance. FEMS Microbiol Rev 32, 361-85. 